\title{
Desempenho agronômico da soja cultivada em diferentes épocas e distribuição de plantas
}

\author{
Soybean performance at different sowing times and plant distribution
}

\section{Eduardo Lima do Carmo, Guilherme Braga Pereira Braz*, Gustavo André Simon, Alessandro Guerra da Silva \& Antônio Germano Carpim Rocha}

Universidade de Rio Verde, Rio Verde, GO, Brasil. *Autor para correspondência: guilhermebrag@gmail.com.

Submissão: 13/05/2017 | Aceite: 30/10/2017

\begin{abstract}
RESUMO
Períodos favoráveis à semeadura bem como a disposição espacial em que plantas se encontram na área de cultivo são fatores que influenciam diretamente a produtividade da soja. A melhor equidistância entre plantas para determinada época de cultivo pode resultar em maior aproveitamento de água, luz e nutrientes. Nesse contexto, por duas safras agrícolas de verão contínuas, foram realizados experimentos de campo com o objetivo de avaliar o desempenho agronômico da soja semeada em diferentes épocas e distribuição espacial de plantas. O delineamento utilizado foi de blocos casualizados, em esquema de parcelas subdivididas, com quatro repetições. Nas parcelas, foram alocadas quatro épocas de semeadura equidistantes de 15 dias a partir de 3 de outubro (2014/15 e 2015/16) e nas subparcelas foram dispostos, aleatoriamente, os espaçamentos entre linhas de semeadura de 0,5 e 0,25 m (tradicional e adensado, respectivamente). Na colheita, avaliaram-se características morfológicas, componentes do rendimento e a produtividade de grãos. A época de semeadura influenciou as características morfológicas e componentes do rendimento da soja. O retardamento da época de semeadura proporcionou menores rendimentos de grãos. As cultivares de soja se comportaram de maneira distinta quanto à redução no espaçamento entre linhas. A BMX Desafio $\mathrm{RR}^{\circledR}$ apresentou maior produtividade quando cultivada em espaçamento entre linhas de $0,25 \mathrm{~m}$ em relação ao tradicional $(0,5 \mathrm{~m})$.
\end{abstract}

PALAVRAS-CHAVE: arranjo espacial de plantas, Glycine max, plasticidade fenotípica.

\begin{abstract}
Favorable periods to sowing as well as the spatial arrangement in which plants are found in the growing area are factors that directly influence soybean yield. The best equidistance between plants for a certain growing period may result in greater use of water, light and nutrients by plants. In this context, in two summer's crops, two field trials were carried out in order to evaluate the agronomic performance of soybean grown at different sowing periods and spatial plant distribution. The experimental design was a randomized complete block design in subdivided plots with four replications. In the plots, four equidistant sowing periods of 15 days from October 3 (2014/15 and 2015/16) were allocated and in the subplots, we arranged, randomly, the traditional and narrow plant spacing (inter-row spacing of $0.5 \mathrm{~m}$ and $0.25 \mathrm{~m}$, respectively). At harvest, morphological characteristics, yield components and grain yield were evaluated. The sowing time influenced the morphological characteristics and yield components of soybean. Delaying the sowing season provided lower grain yields. Soybean cultivars behave differently in relation to the reduction of sowing inter-row spacing. BMX Desafio $R^{\circledR}$ presented higher yield when cultivated in $0.25 \mathrm{~m}$ inter-row spacing compared to traditional spacing $(0.5 \mathrm{~m})$.
\end{abstract}

KEYWORDS: plant spatial arrangements, Glycine max, phenotypic plasticity.

\section{INTRODUÇÃO}

Cultivares de soja, em sua maioria, apresentam características de alta plasticidade, ou seja, capacidade de se adaptar às condições ambientais e de manejo, por meio de modificações na morfologia e nos componentes do rendimento (FERREIRA JUNIOR et al. 2010). Essa particularidade está relacionada à adaptação a altitude, latitude, fertilidade do solo, época de semeadura, população de plantas e espaçamentos entre linhas diferenciados. Portanto, é importante conhecer as interações entre esses fatores para definir práticas de manejo que favoreçam o aumento de rendimento de grãos da cultura, mesmo que 
os componentes de produtividade da soja variem, também, em função das cultivares utilizadas (HEIFFIG et al. 2006).

A época de implantação da cultura consiste em um dos fatores que tem maior efeito sobre a produtividade de grãos, visto que terá influência direta na arquitetura das plantas, podendo modificá-la de acordo com a época em que se realiza a semeadura. Neste sentido, CRUZ et al. (2010) demonstraram que o retardamento na implantação da cultura da soja para épocas mais tardias proporciona produtividade mais baixa em relação à semeadura realizada em épocas mais precoces.

Há de se ressaltar que as novas cultivares de soja apresentam hábito de crescimento indeterminado e porte mais baixo, com menor tamanho de trifólios, os quais se encontram inseridos em ângulos mais agudos na haste (ZANON et al. 2016). Características essas diferentes das primeiras linhagens introduzidas no Brasil, o que vem promovendo mudanças nos ajustes fitotécnicos de semeadura (arranjo de plantas), visto que a maioria dos materiais apresenta características de alta plasticidade (SOUZA et al. 2010).

A semeadura em espaçamentos adensados tem sido estudada no intuito de aumentar o rendimento de grãos em soja. Essa prática promove o aumento da tolerância da planta ao desfolhamento (FONTOURA et al. 2006), permite a redução de perdas de água do solo por evaporação (ÇALIŞKAN et al. 2007), maior intercepção de luz no início do ciclo de desenvolvimento da planta (EDWARDS et al. 2005), além de influenciar positivamente no controle cultural de plantas daninhas (BIANCHI et al. 2010). Apesar disso, a semeadura adensada da soja também apresenta limitações, destacando-se a indisponibilidade de semeadoras no mercado com espaçamentos entre linhas reduzidos (KUSS 2006), assim como aumento na severidade de doenças como a ferrugem asiática (LIMA et al. 2012).

Conforme a cultivar implantada e época de plantio, já foram registrados aumentos de produtividade com a implantação de soja em espaçamentos adensados (BALBINOT JÚNIOR et al. 2013). Nesse sentido, trabalhos de pesquisa são necessários para elucidar os efeitos das épocas de semeadura e distribuição de plantas para cultivares de soja de arquitetura moderna, em especial nas condições do Cerrado brasileiro. Em caso de viabilidade do cultivo da soja em espaçamentos mais adensados, essa tecnologia poderá auxiliar positivamente o manejo da cultura, favorecendo a sustentabilidade da exploração agrícola desta espécie vegetal.

Este trabalho teve por objetivo avaliar o desempenho agronômico da soja semeada em diferentes épocas e a distribuição espacial de plantas.

\section{MATERIAL E MÉTODOS}

Dois experimentos foram conduzidos a campo no município de Rio Verde, estado de Goiás (17 $47^{\prime} 53^{\prime \prime}$; $51^{\circ} 55^{\prime} 53^{\prime \prime} \mathrm{W}$ e $756 \mathrm{~m}$ de altitude), nas safras agrícolas 2014/15 e 2015/16.

O solo da área experimental foi classificado como Latossolo Vermelho distroférrico (EMBRAPA 2013), o qual em análise química realizada na primeira safra (2014/15) apresentou os seguintes resultados: $24,9 \mathrm{~g} \mathrm{dm}^{-3}$ de M.O.; 5,4 de $\mathrm{pH}$ em CaCl $2 ; 5,5 \mathrm{mg} \mathrm{dm}^{-3}$ de P; $0,51 \mathrm{cmol}_{\mathrm{c}} \mathrm{dm}^{-3} \mathrm{de} \mathrm{K} ; 3,18 \mathrm{cmol}_{\mathrm{c}} \mathrm{dm}^{-3} \mathrm{de} \mathrm{Ca}$; $1,52 \mathrm{cmol}_{\mathrm{c}} \mathrm{dm}^{-3}$ de $\mathrm{Mg}$ e $51,29 \%$ de saturação de bases. Em ambas as safras, a cultura antecessora foi o milho. Os dados de precipitação e temperatura média do ar, durante a condução dos experimentos (safras 2014/15 e 2015/16), encontram-se representados na Figura 1.

Os experimentos foram conduzidos em delineamento de blocos casualizados em esquema de parcelas subdivididas, adotando-se quatro repetições. Nas parcelas, foram alocadas quatro épocas de semeadura, equidistantes em 15 dias a partir de 03 de outubro (03/10; 18/10; 02/11; e 17/11). Nas subparcelas, foram dispostos dois espaçamentos de semeadura: tradicional e adensado, sendo estes representados por 0,5 e 0,25 m entre linhas, respectivamente.

As parcelas constituíram-se de $11 \mathrm{~m}$ de comprimento por $2 \mathrm{~m}$ de largura com um corredor central de $1 \mathrm{~m}$, o qual separava as subparcelas, totalizando área bruta de $22 \mathrm{~m}^{2}$. A área útil foi obtida com duas e quatro linhas centrais para os respectivos formatos de semeadura (tradicional e adensado), desconsiderando $1 \mathrm{~m}$ de cada extremidade, perfazendo $3 \mathrm{~m}^{2}$ por subparcela, com número aproximado de 120 plantas.

Aos dez dias antecedendo a primeira época de semeadura da soja, para ambos os experimentos, foi realizada a dessecação de manejo das plantas daninhas presentes na área com aplicação do herbicida glyphosate (1.200 g e.a. ha- $\left.{ }^{-1}\right)$. As sementes foram tratadas com thiametoxam + [fipronil + piraclostrobina + tiofanato metílico $\left(105+[60+6+54] \mathrm{g}\right.$ i.a. $100 \mathrm{~kg}$ de sementes $\left.{ }^{-1}\right)$ e inoculante líquido composto das estirpes Semia 5079 e 5080 em concentração de $6 \times 10^{-9}$ unidades formadoras de colônia, na proporção de $50 \mathrm{~mL}^{5} \mathrm{~kg}$ de sementes ${ }^{-1}$. 


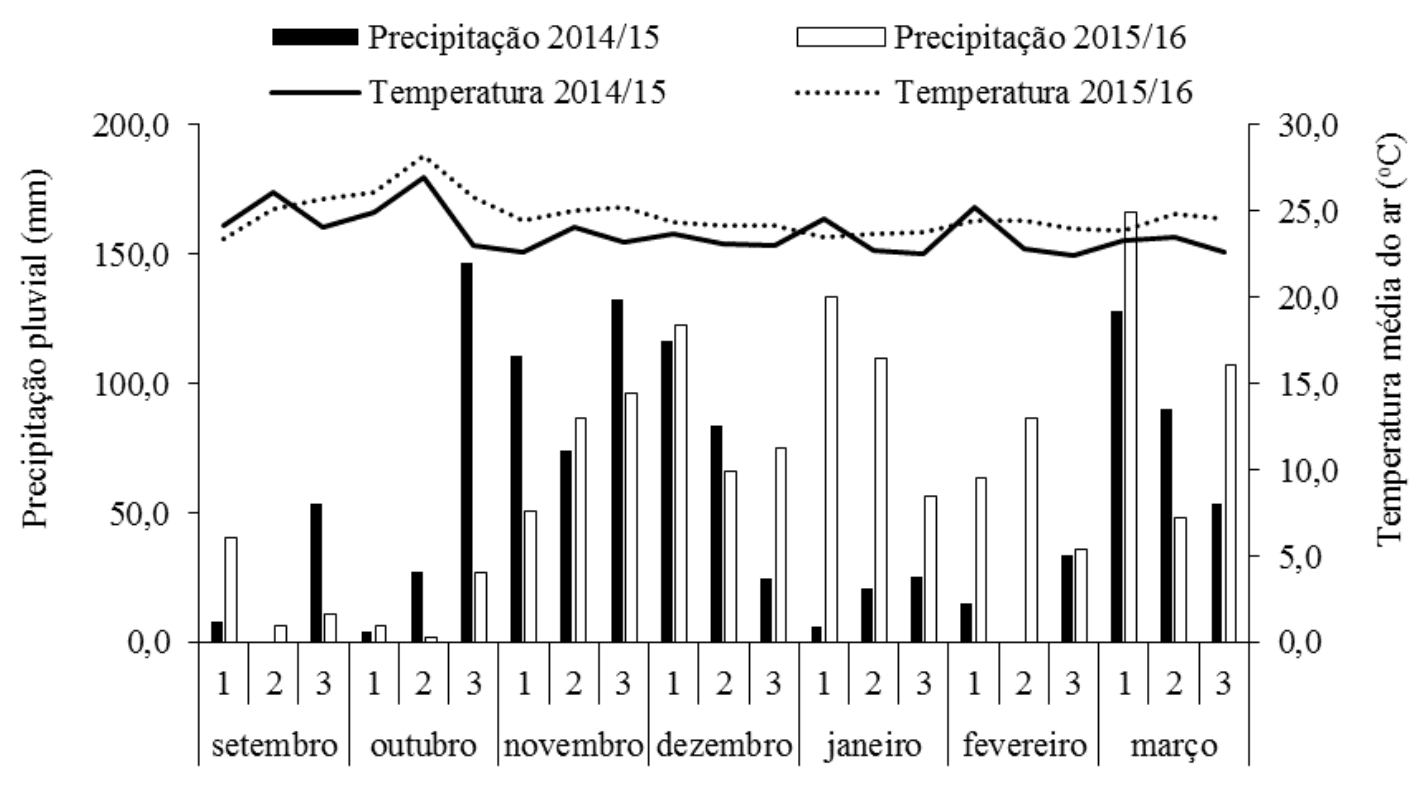

Meses (decêndios)

Figura 1. Precipitação pluvial e temperatura média do ar em Rio Verde (GO) durante as safras de verão compreendidas entre os anos de 2014 e 2016.

Figure 1. Rainfall and average temperature in Rio Verde (GO) during summer seasons between 2014 and 2016.

Aos dez dias antecedendo a primeira época de semeadura da soja, para ambos os experimentos, foi realizada a dessecação de manejo das plantas daninhas presentes na área com aplicação do herbicida glyphosate $\left(1.200 \mathrm{~g}\right.$ e.a. ha $\left.^{-1}\right)$. As sementes foram tratadas com thiametoxam + [fipronil + piraclostrobina + tiofanato metílico $\left(105+[60+6+54] \mathrm{g}\right.$ i.a. $100 \mathrm{~kg}$ de sementes $\left.{ }^{-1}\right)$ e inoculante líquido composto das estirpes Semia 5079 e 5080 em concentração de $6 \times 10^{-9}$ unidades formadoras de colônia, na proporção de $50 \mathrm{~mL}^{5} \mathrm{~kg}$ de sementes ${ }^{-1}$.

As semeaduras foram realizadas com semeadora-adubadora com mecanismo cônico de distribuição contínuo de sementes, equipada com 7 discos duplos excêntricos, distantes de 0,25 m. A adubação de base foi realizada com a aplicação antecipada (sete dias antecedendo a semeadura) de $3 \mathrm{t} \mathrm{ha}^{-1}$ de cama de aviário de corte $\left(8^{\circ}\right.$ lote), e na semeadura foram aplicados com haste sulcadora $300 \mathrm{~kg} \mathrm{ha}^{-1}$ do adubo formulado 02-20-18 (N-P-K). Além disso, quinze dias após a semeadura da soja, foi realizada aplicação a lanço de $100 \mathrm{~kg} \mathrm{ha}^{-1}$ de cloreto de potássio.

No primeiro experimento, conduzido na safra 2014/15, utilizou-se a cultivar de soja BMX Potência $\mathrm{RR}^{\circledR}$ (hábito de crescimento indeterminado, grupo de maturidade 7,0 e população de 400.000 plantas ha-1). Para o segundo experimento (safra 2015/16), foi utilizada na semeadura a cultivar BMX Desafio RR $^{\circledR}$ (hábito de crescimento indeterminado, grupo de maturidade 7,4 e população de 400.000 plantas ha ${ }^{-1}$ ). Levou-se em consideração na escolha de ambas as cultivares a expressiva área de cultivo que elas apresentam na região em que os experimentos foram conduzidos.

Para semeaduras compreendidas no mês de outubro, como forma de garantir a emergência das plântulas de soja, foi realizada irrigação via mangueira perfurada. Aos dez dias da emergência, efetuou-se desbaste manual das plântulas de soja de forma a estabelecer a distribuição espacial desejada em cada tratamento alocado na unidade experimental. Os tratos culturais referentes ao controle de plantas daninhas, pragas e doenças foram efetuados conforme recomendações técnicas para a cultura da soja (EMBRAPA 2008).

$\mathrm{Na}$ ocasião da colheita, foram realizadas avaliações na área útil das parcelas referentes a: alturas de plantas e de inserção da primeira vagem, cuja medida foi realizada do solo até a extremidade do último racemo floral e de inserção da primeira vagem, respectivamente; assim como o número de ramificações, de vagens por planta e de grãos por vagem. Essas avaliações foram realizadas em quinze plantas contínuas presentes na linha central das unidades experimentais. Além disso, foi avaliada também a massa de mil 
grãos e produtividade de grãos da soja, sendo em ambos os casos adotada correção da umidade para $13 \%$.

As análises estatísticas foram realizadas com o programa Sisvar ${ }^{\circledR}$ (FERREIRA 2011). Os dados foram submetidos à análise de variância e quando constatada significância, foi empregada a análise de regressão e o teste de Tukey $(p \leq 0,05)$ para comparação das médias entre as épocas de semeadura e espaçamento entre linhas, respectivamente.

\section{RESULTADOS E DISCUSSÃO}

À exceção do número de vagens por planta da cultivar $B M X$ Desafio $R^{\circledR}$, houve efeito significativo da época de semeadura da soja para todas as variáveis-respostas de ambos os experimentos (Tabela 1). A cultivar BMX Potência $\operatorname{RR}^{\circledR}$ (2014/15), quanto ao número de ramificações, foi influenciada pela disposição das plantas, bem como a interação desse fator com a época de semeadura. Entretanto, esse fato não foi observado no segundo experimento (2015/16), porém a produtividade da cultivar BMX Desafio RR $^{\circledR}$ diferiu entre os espaçamentos entre linhas.

Tabela 1. Resumo da análise de variância para as variáveis alturas de plantas (AP), altura de inserção da primeira vagem (AIPV), números de ramificações (RAM), número de vagens por planta (V/P), número de grãos por vagem (G/V), massa de mil grãos (MMG) e produtividade de grãos (PG).

Table 1. ANOVA summary for the variables plant height (AP) and height of insertion of first pod (AIVP), number of branches (RAM), number of pods per plant (V/P), number of grains per pod $(G / V)$, mass of 1,000 grains (MMG) and grain yield (PG).

\begin{tabular}{|c|c|c|c|c|c|c|c|c|}
\hline \multirow{2}{*}{ Fontes de variação } & \multirow{2}{*}{ GL } & \multicolumn{7}{|c|}{ Valores de F calculado } \\
\hline & & AP & AIPV & RAM & $\mathrm{V} / \mathrm{P}$ & $\mathrm{G} / \mathrm{V}$ & MMG & $P G$ \\
\hline & & \multicolumn{7}{|c|}{ BMX Potência RR ${ }^{\circledR}(2014 / 15)$} \\
\hline Época de semeadura & 3 & $26,1^{* *}$ & $4,3^{*}$ & $11,9^{* *}$ & $38,1^{* *}$ & $48,5^{* *}$ & $51,5^{\star *}$ & $42,6^{* *}$ \\
\hline Erro 1 & 9 & & & & & & & \\
\hline Espaçamento & 1 & $0,6^{\text {ns }}$ & $1,7^{\mathrm{ns}}$ & $13,7^{* *}$ & $9,3^{* *}$ & $2,3^{\text {ns }}$ & $0,02^{\text {ns }}$ & $3,5^{\mathrm{ns}}$ \\
\hline Época x Espaçamento & 3 & $0,9^{\text {ns }}$ & $1,0^{\text {ns }}$ & $8,6^{\star *}$ & $0,6^{\text {ns }}$ & $2,2^{\text {ns }}$ & $1,6^{\text {ns }}$ & $2,1^{\text {ns }}$ \\
\hline Erro 2 & 12 & & & & & & & \\
\hline CV1(\%) & & 5,9 & 13,6 & 27,7 & 11,5 & 4,7 & 7,1 & 10,0 \\
\hline \multirow[t]{2}{*}{ CV2(\%) } & & 5,0 & 14,2 & 16,2 & 7,5 & 3,7 & 3,4 & 9,4 \\
\hline & & \multicolumn{7}{|c|}{ BMX Desafio RR ${ }^{\circledR}(2015 / 16)$} \\
\hline Época de semeadura & 3 & $25,3^{* *}$ & $70,8^{* *}$ & $18,4^{* *}$ & $2,6^{\text {ns }}$ & $44,5^{* *}$ & $94,4^{* *}$ & $30,1^{* *}$ \\
\hline Erro 1 & 9 & & & & & & & \\
\hline Espaçamento & 1 & $0,9^{\text {ns }}$ & $2,7^{\mathrm{ns}}$ & $2,0^{\text {ns }}$ & $21,7^{* *}$ & $1,2^{\text {ns }}$ & $0,7^{\text {ns }}$ & $7,6^{* *}$ \\
\hline Época x Espaçamento & 3 & $1,7^{\text {ns }}$ & $3,3^{\text {ns }}$ & $3,3^{\text {ns }}$ & $4,0^{* *}$ & $0,6^{\text {ns }}$ & $0,4^{\text {ns }}$ & $0,6^{\mathrm{ns}}$ \\
\hline Erro 2 & 12 & & & & & & & \\
\hline CV1(\%) & & 4,9 & 8,5 & 21,3 & 11,7 & 5,8 & 4,5 & 6,7 \\
\hline CV2(\%) & & 3,8 & 7,2 & 11,2 & 5,8 & 4,8 & 5,9 & 6,8 \\
\hline
\end{tabular}

${ }^{* *, *} e^{\text {ns }}$ Significativo a 1 e $5 \%$ de probabilidade e não significativo pelo Teste de $f$, respectivamente.

Para altura de plantas de soja na ocasião da colheita, não foi verificado efeito significativo em função dos diferentes espaçamentos entre linhas (Tabela 2). Esses resultados corroboram com os observados por CARVALHO (2014), o qual não observou para a cultivar de hábito de crescimento indeterminado V-Max $R^{\circledR}$ influência na altura das plantas utilizando espaçamentos entre linhas de 0,4 e 0,2 m. Por outro lado, ORMOND (2013) verificou maiores alturas de plantas de soja cultivar Anta 82 RR $^{\circledR}$ para semeadura com arranjo em linhas cruzadas ("plantio cruzado") e altas populações de plantas por hectare. Segundo o autor, as maiores alturas de plantas ocorreram devido ao estiolamento, representando uma tentativa de adaptação pela competição intraespecífica das plantas de soja por luminosidade.

Por meio das equações ajustadas para a variável altura de plantas, foi possível observar que plantas de soja com maiores alturas foram obtidas com a semeadura realizada em, aproximadamente, 24 de outubro e 02 de novembro, para as cultivares $B M X$ Potência $R R^{\circledR}$ e BMX Desafio $R R^{\circledR}$, respectivamente (Tabela 2). Para semeaduras realizadas a partir dessas datas, foi verificada a obtenção de plantas com 
menor estatura, fato que já foi constatado previamente na literatura, demonstrando a importância de se respeitar o intervalo de semeadura para a cultura da soja (STÜLP et al. 2009).

Tabela 2. Altura de plantas (AP) e altura de inserção da primeira vagem (AIPV) para soja cultivada em diferentes épocas e distribuição de plantas.

Table 2. Plant height (AP) and height of insertion of the first pod (AIPV) for soybean grown in different periods and plant distribution.

\begin{tabular}{|c|c|c|c|c|c|c|}
\hline \multirow{3}{*}{ Semeadura } & \multicolumn{3}{|c|}{ AP $(\mathrm{cm})$} & \multicolumn{3}{|c|}{ AIPV (cm) } \\
\hline & \multicolumn{6}{|c|}{ BMX Potência RR $^{\circledR}(2014 / 15)$} \\
\hline & Tradicional & Adensado & Média & Tradicional & Adensado & Média \\
\hline 03 de outubro & 68,7 & 71,2 & 70,0 & 11,6 & 11,8 & 11,7 \\
\hline 18 de outubro & 76,9 & 76,7 & 76,8 & 13,1 & 13,2 & 13,2 \\
\hline 02 de novembro & 80,2 & 83,5 & 81,3 & 14,7 & 13,3 & 14,0 \\
\hline 17 de novembro & 64,9 & 63,1 & 64,0 & 16,1 & 13,6 & 14,8 \\
\hline Média & $72,7 \mathrm{a}$ & $73,6 \mathrm{a}$ & & $13,9 \mathrm{a}$ & $13,0 \mathrm{a}$ & \\
\hline \multirow{2}{*}{\multicolumn{3}{|c|}{$y A P=68,9069+1,1475 x-0,0274 x^{2} ; R^{2}=88$}} & \multicolumn{4}{|c|}{$y A I P V=11,8687+0,0685 x ; R^{2}=98$} \\
\hline & & & \multicolumn{4}{|c|}{ BMX Desafio $R^{\circledR}(2015 / 16)$} \\
\hline 03 de outubro & 61,6 & 63,9 & 62,8 & 7,4 & 9,4 & 8,4 \\
\hline 18 de outubro & 74,9 & 72,1 & 73,5 & 14,8 & 13,9 & 14,4 \\
\hline 02 de novembro & 75,9 & 78,5 & 77,2 & 15,2 & 16,3 & 15,8 \\
\hline 17 de novembro & 72,9 & 74,5 & 73,7 & 15,1 & 15,3 & 15,2 \\
\hline Média & $71,3 \mathrm{a}$ & $72,2 \mathrm{a}$ & & $13,2 \mathrm{a}$ & $13,7 \mathrm{a}$ & \\
\hline \multicolumn{4}{|c|}{$y A P=62,7481+0,9537 x-0,0157 x^{2} ; R^{2}=99$} & \multicolumn{3}{|c|}{$y A I P V=8,5327+0,4704 x-0,0072 x^{2} ; R^{2}=99$} \\
\hline
\end{tabular}

A semeadura realizada de maneira muito antecipada bem como o atraso na realização dessa operação (03 de outubro e 17 de novembro) restringiram o crescimento da soja, fato que provavelmente está relacionado às condições de fotoperíodo a que as plantas foram submetidas (JOHNSON et al. 1960). Apesar disso, os valores obtidos foram de aproximadamente 70 a $80 \mathrm{~cm}$ de altura, o qual é considerado ideal para realização da colheita mecanizada (SEDIYAMA 2009).

De maneira análoga à altura de plantas, para a variável altura de inserção da primeira vagem não foi observada influência dos diferentes espaçamentos entre linhas utilizados na semeadura da soja (Tabela 2). Em relação ao efeito das diferentes épocas de semeadura sobre a altura de inserção da primeira vagem, foi observado acréscimo nos valores para semeaduras realizadas mais tardiamente, verificando ajuste linear e quadrático dos dados, respectivamente, para a as cultivares BMX Potência $R^{\circledR}{ }^{\circledR}(2014 / 15)$ e BMX Desafio $\mathrm{RR}^{\circledR}(2015 / 16)$. Em trabalho realizado na região noroeste do Paraná, resultados semelhantes foram observados, uma vez que o atraso na semeadura proporcionou plantas de soja com maiores alturas de inserção da primeira vagem (BARBOSA et al. 2013).

A variável supracitada tem relação com o aproveitamento de luz na camada inferior do dossel, ou seja, quanto maior a radiação direta na porção inferior do dossel, mais baixo será o nó da primeira vagem e, por consequência, a altura de inserção da primeira vagem (ZABOT 2009). A escolha da cultivar, bem como das práticas de manejo, deve buscar atingir altura de inserção da primeira vagem de pelo menos $10 \mathrm{~cm}$ para evitar que perdas na colheita mecanizada sejam observadas (CARVALHO et al. 2010). No presente trabalho, isso não ocorreu para a cultivar BMX Desafio $R^{\circledR}{ }^{\circledR}(2015 / 16)$ em sua primeira época de semeadura.

No número de ramificações por planta, foi constatada interação significativa entre as fontes de variação testadas para a cultivar BMX Potencia $R^{\circledR}{ }^{\circledR}$, na safra 2014/15 (Tabelas 1 e 3). Esse resultado indica que, para ambos os espaçamentos, houve acréscimo de ramos com o atraso da semeadura, à exceção da terceira época, na qual se observa uma diminuição da referida característica, provavelmente devido aos índices de precipitação e radiação difusa na fase vegetativa, nos meses de novembro e dezembro. Consequentemente, houve o estiolamento da planta, direcionando as reservas para 0 crescimento da haste principal ao invés das hastes secundárias, o que pode ser observado na característica de altura de plantas (Tabela 2). 
O maior número de ramificações, na $3^{a}$ e $4^{a}$ épocas de semeadura, em espaçamento de $0,5 \mathrm{~cm}$, na safra 2014/15, pode ter ocorrido devido à melhor penetração de radiação na parte basal no início do desenvolvimento das plantas, proporcionando maior estímulo à brotação das gemas vegetativas.

Para o experimento com a cultivar BMX Desafio $\mathrm{RR}^{\circledR}$, observou-se decréscimo linear do número de ramificações por planta, à medida que a semeadura da soja foi realizada mais tardiamente. Além disso, não foi observada influência dos diferentes espaçamentos entre linhas utilizados na semeadura sobre a variável analisada. De forma semelhante, COSTA (2013) também verificou que a semeadura da soja realizada com espaçamentos entre linhas de 0,2; 0,4 e 0,6 m não afetou o número de ramificações das cultivares BMX Potência $\mathrm{RR}^{\circledR}$ e NA $5909 \mathrm{RR}^{\circledR}$.

Tabela 3. Número de ramificações (RAM) e número de vagens por planta (V/P) para soja cultivada em diferentes épocas e distribuição de plantas.

Table 3. Number of branches (RAM) and number of pods per plant (V/P) for soybean grown in different periods and plant distribution.

\begin{tabular}{|c|c|c|c|c|c|c|}
\hline \multirow{3}{*}{ Semeadura } & \multicolumn{3}{|c|}{ RAM } & \multicolumn{3}{|c|}{$\mathrm{V} / \mathrm{P}$} \\
\hline & \multicolumn{6}{|c|}{ BMX Potência RR ${ }^{\circledR}(2014 / 15)$} \\
\hline & Tradicionalt $^{t}$ & Adensado $^{a}$ & Média & Tradicional $^{t}$ & Adensado $^{a}$ & Média \\
\hline 03 de outubro & $1,6 \mathrm{a}$ & $2,0 \mathrm{a}$ & 1,8 & 34,6 & 38,3 & 36,4 \\
\hline 18 de outubro & $2,4 \mathrm{a}$ & $2,2 \mathrm{a}$ & 2,3 & 30,6 & 33,5 & 32,0 \\
\hline 02 de novembro & $1,9 \mathrm{a}$ & $0,9 \mathrm{~b}$ & 1,4 & 23,7 & 24,8 & 24,2 \\
\hline 17 de novembro & $3,6 \mathrm{a}$ & $2,6 \mathrm{~b}$ & 3,1 & 20,1 & 21,7 & 20,9 \\
\hline Média & $2,4 \mathrm{a}$ & $1,9 \mathrm{~b}$ & & $27,2 \mathrm{~b}$ & \multicolumn{2}{|l|}{$29,5 \mathrm{a}$} \\
\hline \multicolumn{4}{|c|}{$\operatorname{yRAM}^{t}=1,7733-0,0102 x+0,001 x^{2} ; R^{2}=75$} & & & \\
\hline \multicolumn{7}{|c|}{ yRAM $^{a}=2,2585-0,0751 x+0,0017 x^{2} ; R^{2}=36$} \\
\hline & \multicolumn{6}{|c|}{ BMX Desafio RR $^{\circledR}(2015 / 16)$} \\
\hline 03 de outubro & 3,0 & 2,8 & 2,9 & $33,3 \mathrm{~b}$ & $40,9 \mathrm{a}$ & 37,1 \\
\hline 18 de outubro & 2,2 & 2,5 & 2,3 & $39,0 \mathrm{a}$ & $42,3 \mathrm{a}$ & 40,7 \\
\hline 02 de novembro & 1,9 & 1,8 & 1,9 & $41,8 \mathrm{a}$ & $41,6 \mathrm{a}$ & 41,7 \\
\hline 17 de novembro & 1,5 & 1,1 & 1,3 & $34,3 \mathrm{~b}$ & $38,4 \mathrm{a}$ & 36,3 \\
\hline \multirow[t]{3}{*}{ Média } & $2,1 \mathrm{a}$ & $2,0 \mathrm{a}$ & & $37,1 \mathrm{~b}$ & $40,8 \mathrm{a}$ & \\
\hline & & & \multicolumn{4}{|c|}{$y V / P^{t}=32,9600+0,6951 x-0,01460 x^{2} ; R^{2}=94$} \\
\hline & & & \multicolumn{4}{|c|}{$y V / P^{a}=1,9138+0,0119 x ; R^{2}=60$} \\
\hline
\end{tabular}

* Médias seguidas de mesma letra, na linha, dentro de cada cultivar não diferem entre si pelo teste de Tukey $(p \leq 0,05)$.

Houve redução no número de vagens produzidas por planta à medida que se avançou nas datas de semeadura da soja cultivar BMX Potencia $R^{\circledR}{ }^{\circledR}$ (Tabela 3). Semelhante influência da época de semeadura no número de vagens produzidas por planta de soja foi verificada por STÜLP et al. (2009). Para a cultivar BMX Desafio $R^{\circledR}{ }^{\circledR}$, apenas os espaçamentos e a interação desses com a época de semeadura tiveram diferenças no número de vagens produzidas por planta. Para essa cultivar, verificaram-se maiores quantidades de vagens por planta para o arranjo adensado $(0,25 \mathrm{~m})$, fato que pode ser explicado pela distribuição mais equidistante das plantas, proporcionando maior uniformidade no crescimento e desenvolvimento da soja.

Em ambos os experimentos conduzidos, o número de grãos por vagem foi afetado somente pelas épocas de semeadura, observando-se aumento nos valores dessa variável-resposta à medida que a semeadura fora realizada mais tardiamente (Tabela 4). Segundo BOARD (2000), o número de grãos por vagem é uma característica intrínseca da planta e, normalmente, não é afetado por práticas de manejo como a redução do espaçamento entre linhas na semeadura, ou eventuais mudanças na população de plantas por hectare.

A variável massa de mil grãos foi afetada pelas épocas de semeadura, não sendo influenciada pela distribuição de plantas (Tabela 4). Semeaduras realizadas entre 18 de outubro e 02 de novembro com cultivar BMX Potencia $\mathrm{RR}^{\circledR}$ apresentaram valores de massa de mil grãos inferiores aos observados nas demais épocas, verificando menor valor estimado desta variável para semeadura da soja realizada em 27 de outubro. Analisando o ciclo de desenvolvimento da soja para a semeadura realizada no período 
mencionado acima, relaciona-se a observação dos menores valores de massa de mil grãos ao fato de que, para estas épocas de semeadura, a fase de enchimento de grãos da cultura coincidiu com a ocorrência de veranicos na região.

Nessa situação, a menor disponibilidade de água para as plantas reduz as taxas fotossintéticas e o período de enchimento de grãos. Consequentemente, há diminuição no acúmulo de fotoassimilados nos grãos, o que impacta negativamente na produtividade (HEIFFIG et al. 2006).

Tabela 4. Número de grãos por vagem (G/V) e massa de mil grãos (MMG) para soja cultivada em diferentes épocas e distribuição de plantas.

Table 4. Number of grains per pod (G/V) and mass of 1,000 grains (MMG) for soybean grown in different periods and plant distribution.

\begin{tabular}{|c|c|c|c|c|c|c|}
\hline \multirow{3}{*}{ Semeadura } & \multicolumn{3}{|c|}{ G/V } & \multicolumn{3}{|c|}{ MMG (g) } \\
\hline & \multicolumn{6}{|c|}{ BMX Potência RR ${ }^{\circledR}(2014 / 15)$} \\
\hline & Tradicional & Adensado & Média & Tradicional & Adensado & Média \\
\hline 03 de outubro & 2,0 & 2,1 & 2,1 & 173 & 171 & 172 \\
\hline 18 de outubro & 2,6 & 2,5 & 2,6 & 136 & 140 & 138 \\
\hline 02 de novembro & 2,7 & 2,7 & 2,7 & 112 & 116 & 114 \\
\hline 17 de novembro & 2,7 & 2,7 & 2,7 & 166 & 161 & 163 \\
\hline Média & $2,5 \mathrm{a}$ & $2,5 \mathrm{a}$ & & $147 \mathrm{a}$ & $147 \mathrm{a}$ & \\
\hline \multirow{2}{*}{\multicolumn{3}{|c|}{$y G / V=2,0893+0,0360 x-0,0005 x^{2} ; R^{2}=99$}} & \multicolumn{4}{|c|}{$y M M G=175,4100-4,5454 x+0,0935 x^{2} ; R^{2}=91$} \\
\hline & & & \multicolumn{4}{|c|}{ BMX Desafio RR ${ }^{\circledR}(2015 / 16)$} \\
\hline 03 de outubro & 1,8 & 1,7 & 1,7 & 212 & 207 & 209 \\
\hline 18 de outubro & 2,4 & 2,3 & 2,3 & 185 & 179 & 182 \\
\hline 02 de novembro & 2,3 & 2,2 & 2,3 & 164 & 168 & 166 \\
\hline 17 de novembro & 2,4 & 2,4 & 2,4 & 148 & 143 & 145 \\
\hline Média & $2,2 \mathrm{a}$ & $2,1 \mathrm{a}$ & & $177 \mathrm{a}$ & $174 \mathrm{a}$ & \\
\hline
\end{tabular}

${ }^{*}$ Médias seguidas de mesma letra, na linha, dentro de cada cultivar não diferem entre si pelo teste de Tukey $(p \leq 0,05)$.

Tabela 5. Produtividade de grãos da soja cultivada em diferentes épocas e distribuição de plantas.

Table 5. Grain yield of soybean grown in different periods and plant distribution.

\begin{tabular}{|c|c|c|c|c|c|c|}
\hline \multirow{3}{*}{ Semeadura } & \multicolumn{6}{|c|}{ Produtividade (kg ha-1) } \\
\hline & \multicolumn{3}{|c|}{ BMX Potência RR ${ }^{\circledR}(2014 / 15)$} & \multicolumn{3}{|c|}{ BMX Desafio RR ${ }^{\circledR}(2015 / 16)$} \\
\hline & Tradicional & Adensado & Média & Tradicional & Adensado & Média \\
\hline 03 de outubro & 4301 & 4997 & 4649 & 4495 & 4874 & 4685 \\
\hline 18 de outubro & 3773 & 3929 & 3851 & 5924 & 6128 & 6026 \\
\hline 02 de novembro & 2824 & 2989 & 2906 & 5640 & 6266 & 5953 \\
\hline 17 de novembro & 3022 & 2897 & 2959 & 4793 & 5008 & 4901 \\
\hline Média & $3480 \mathrm{a}$ & $3703 \mathrm{a}$ & & $5213 \mathrm{~b}$ & $5569 \mathrm{a}$ & \\
\hline \multicolumn{4}{|c|}{$y P G=4493,6868-40,0961 x ; R^{2}=88$} & \multicolumn{3}{|c|}{$y P G=4706,5653+123,5243 x-2,6598 x^{2} ; R^{2}=99$} \\
\hline
\end{tabular}

Para a cultivar BMX Desafio $\mathrm{RR}^{\circledR}$, a massa de mil grãos apresentou comportamento decrescente à medida que a semeadura foi postergada, corroborando com os resultados obtidos por COSTA (2013). Isso pode ser explicado pelo número de vagens totais por planta e número de grãos por vagem que, diferentemente, apresentaram comportamento crescente, mostrando assim a influência da relação fonte dreno da planta.

O atraso da semeadura da cultivar BMX Potência $\mathrm{RR}^{\circledR}$ reduziu linearmente a produtividade de grãos (Tabela 5). Esse comportamento também foi observado em outros trabalhos já apresentados na literatura (STÜLP et al. 2009, COSTA 2013). Pelo ajuste do modelo de regressão, observa-se que, para cada dia de atraso na semeadura da referida cultivar, há redução na produtividade de, aproximadamente, $40 \mathrm{~kg} \mathrm{ha}^{-1}$. 
Em semeaduras tardias para a BMX Potência $R^{\circledR}{ }^{\circledR}$ (safra 2014/15), além das plantas de soja estarem sob condições indutivas ao florescimento, o veranico ocorrido no mês de janeiro (Figura 1) pode ter prejudicado o enchimento de grãos, além de provocar abortamento de flores e vagens para as semeaduras realizadas em 18 de outubro, e 02 e 17 de novembro. É oportuno destacar que a fase reprodutiva, principalmente no estádio de enchimento de grãos, consiste no período em que as plantas de soja apresentam maior demanda hídrica (MATZENAUER et al. 2003).

Além disso, o hábito de crescimento indeterminado da cultivar BMX Potência $\mathrm{RR}^{\circledR}$ permite que as plantas vegetem e floresçam simultaneamente, estendendo a duração do período reprodutivo da cultivar. Neste caso, déficits hídricos podem causar impactos negativos na floração e na retenção de vagens (EMBRAPA 2011). A menor disponibilidade de água ocasiona ainda redução da fotossíntese e do período de enchimento de grãos, afetando assim a produtividade (MATZENAUER et al. 2003).

Para a cultivar $B M X$ Desafio $\mathrm{RR}^{\circledR}$, maiores produtividades foram obtidas na segunda e terceira épocas de semeadura, fato que explica a importância da semeadura em períodos com chuvas regularizadas e posicionamento da cultivar de acordo com as recomendações da empresa. Houve influência do arranjo de plantas na produtividade para a cultivar $B M X$ Desafio $R^{\circledR}{ }^{\circledR}$, verificando-se melhor desempenho quando foram utilizados menores espaçamentos entre linhas (arranjo reduzido - 0,25 $\mathrm{m}$ ). A superioridade deste arranjo em relação ao tradicional foi de $356 \mathrm{~kg} \mathrm{ha}^{-1}$.

\section{CONCLUSÃO}

A época de cultivo tem efeito sobre as características morfológicas e componentes do rendimento de plantas de soja. O retardamento da época de semeadura proporciona menores rendimentos de grãos. Conforme a cultivar de soja implantada, o espaçamento entre linhas influencia diferentemente na produtividade. A BMX Desafio $\mathrm{RR}^{\circledR}$ apresentou maior produtividade quando cultivada em espaçamento entre linhas de $0,25 \mathrm{~m}$, em relação ao tradicional $(0,5 \mathrm{~m})$.

\section{AGRADECIMENTOS}

Agradecimento à Universidade de Rio Verde pela concessão de bolsa de pesquisa, a qual tornou viável a execução do presente trabalho.

\section{REFERÊNCIAS}

BALBINOT JÚNIOR AA et al. 2013. Semeadura cruzada na cultura da soja. Londrina: Embrapa Soja. 8p. (Circular Técnica, 98)

BARBOSA MC et al. 2013. Desempenho agronômico e componentes da produção de cultivares de soja em duas épocas de semeadura no Arenito Caiuá. Semina: Ciências Agrárias 34: 945-960.

BIANCHI MA et al. 2010. Papéis do arranjo de plantas e do cultivar de soja no resultado da interferência com plantas competidoras. Planta Daninha 28: 979-991.

BOARD J. 2000. Light interception efficiency and light quality affect yield compensation of soybean at low plant populations. Crop Science 40: 1285-1294.

ÇALIŞKAN S et al. 2007. The effects of row spacing on yield and yield components of full season and double-cropped soybean. Turkish Journal of Agriculture and Forestry 31: 147-154.

CARVALHO ER et al. 2010. Desempenho de cultivares de soja [Glycine max (L.) Merrill] em cultivo de verão no Sul de Minas Gerais. Ciência e Agrotecnologia 34: 892-899.

CARVALHO MM. 2014. Influência de sistemas de semeadura na população de pragas e nas características morfofisiológicas em cultivares de soja. Dissertação (Mestrado em Agronomia). Botucatu: UNESP. 59p.

COSTA ED. 2013. Arranjo de plantas, características agronômicas e produtividade de soja. Dissertação (Mestrado em Agronomia). Botucatu: UNESP. 60p.

CRUZ TV et al. 2010. Efeitos da época de semeadura sobre a composição química e a produtividade de grãos de diversas cultivares de soja no oeste da Bahia. Revista Brasileira de Oleaginosas e Fibrosas 14: 63-71.

EDWARDS JT et al. 2005. Soybean yield and biomass responses to increasing plant population among diverse maturity groups. Crop Science 45: 1778-1785.

EMBRAPA. 2011. Tecnologias de produção de soja: região central do Brasil 2012 e 2013. Londrina: Embrapa Soja. 261p. (Sistemas de Produção, 15).

EMBRAPA. 2013. Sistema brasileiro de classificação de solos. 3.ed. Brasília: Embrapa. 353p.

EMBRAPA. 2008. Tecnologias de produção de soja - região central do Brasil - 2009 e 2010. Londrina: Embrapa Soja. 262p. (Sistemas de Produção, 13).

FERREIRA DF. 2011. Sisvar: a computer statistical analysis system. Ciência e Agrotecnologia 35: 1039-1042.

FERREIRA JUNIOR JA et al. 2010. Avaliação de genótipos de soja em diferentes épocas de plantio e densidade de semeadura no município de Uberaba - MG. FAZU em Revista 7: 13-21. 
Carmo et al.

FONTOURA TB et al. 2006. Efeitos de níveis e épocas de desfolhamento sobre o rendimento e os componentes do rendimento de grãos da soja. Scientia Agraria 7: 49-54.

HEIFFIG LS et al. 2006. Fechamento e índice de área foliar da cultura da soja em diferentes arranjos espaciais. Bragantia 65: 285-295.

JOHNSON HW et al. 1960. Effects of photoperiod and time of planting on rates of development of the soybean in various stages of the life cycle. Botanical Gazette 122: 77-95.

KUSS RCR. 2006. Populações de plantas e estratégias de irrigação na cultura da soja. Dissertação (Mestrado em Engenharia Agrícola). Santa Maria: UFSM. 80p.

LIMA SF et al. 2012. Efeito da semeadura em linhas cruzadas sobre a produtividade de grãos e severidade da ferrugem asiática da soja. Bioscience Journal 28: 954-962.

MATZENAUER R et al. 2003. Estimativa do consumo relativo de água para a cultura da soja no Estado do Rio Grande do Sul. Ciência Rural 33: 1013-1019.

ORMOND ATS. 2013. Sistemas de semeadura e manejo do solo no desenvolvimento da cultura da soja. Dissertação (Mestrado em Engenharia Agrícola). Rondonópolis: UFMT. 71p.

SEDIYAMA T. 2009. Tecnologias de produção e usos da soja. Londrina: Mecenas. 314p.

SOUZA CA et al. 2010. Relação entre densidade de plantas e genótipos de soja Roundup Ready ${ }^{\mathrm{TM}}$. Planta Daninha 28 : 887-896.

STÜLP M et al. 2009. Desempenho agronômico de três cultivares de soja em diferentes épocas de semeadura em duas safras. Ciência e Agrotecnologia 33: 1240-1248.

ZABOT L. 2009. Caracterização agronômica de cultivares transgênicas de soja cultivadas no Rio Grande do Sul. Tese (Doutorado em Agronomia). Santa Maria: UFSM. 280p.

ZANON AJ et al. 2016. Growth habit effect on development of modern soybean cultivars after beginning of bloom in Rio Grande do Sul. Bragantia 75: 446-458. 